\title{
Transplacental xylose transfer in bovine pregnancy
}

\author{
Transferência transplacentária de xilose na prenhez bovina
Marcelo Bertolini, Cynthia Ann Batchelder, Gustavo Ferrer Carneiro, Leticia Esther Valadez, Thomas Richard Famula, Campbell Christopher Calvert, Roberto Daniel Sainz \& Gary Bruce Anderson

\begin{abstract}
A substantial portion of placental function is committed to the regulation of nutrient transfer from the dam to the fetus, with glucose being the major substrate for conceptus metabolism. Due to its homomorphism with glucose, xylose can be used as tracer for the assessment of placental nutrient transfer capacity. This study was designed to evaluate transplacental permeability to xylose in bovine pregnancies on Days 90 and 180 of gestation. In Experiment 1, pregnant and nonpregnant females were infused into the jugular vein or into the allantoic sac with a $10 \%$ xylose solution to evaluate the maternal plasma xylose disappearance and the existence of feto-maternal xylose transfer, respectively. Glucose and xylose concentrations were determined in venous blood samples collected at $0,15,30,60,90,120,150$, and $180 \mathrm{~min}$. A materno-fetal but not a feto-maternal xylose transport was observed in both gestational periods. In Experiment 2, pregnant animals were slaughtered on Days 90 or 180 of gestation. A $10 \%$ xylose solution was infused intravenously into each female 60 min before slaughter to measure the materno-fetal transfer of xylose. Fetal and maternal blood samples and amniotic and allantoic fluids were collected for the determination of glucose and xylose concentrations. An increase in xylose accumulation in the uterine subcompartments was observed toward the end of the second trimester of pregnancy, demonstrating an increase in materno-fetal placental sugar transport as pregnancy advances. In conclusion, xylose can be a valid tracer for studies on transplacental transport with potential implications to conceptus growth in cattle.
\end{abstract}

Key words: placental transport, bovine, xylose, glucose, metabolism.

\section{RESUMO}

Uma porção importante da função placentária é dedicada à regulação da transferência de nutrientes da mãe ao feto, com a glicose sendo o substrato mais expressivo para o concepto. Devido ao homomorfismo com a glicose, a xilose pode ser usada como um marcador para a avaliação da capacidade de tranferência de nutrientes pela placenta. Este estudo visou a avaliação da permeabilidade transplacentária à xilose em fêmeas bovinas nos dias 90 e 180 de gestação. No Experimento 1, fêmeas vazias e prenhes receberam uma infusão de uma solução de $10 \%$ de xilose na veia jugular para a avaliação do desaparecimento da xilose no plasma materno, ou no saco alantóico para a avaliação da existência da transferência fetomaterna de xilose. As concentrações de glicose e xilose foram determinadas em amostras de sangue venoso coletadas aos 0 , 15, 30, 60, 90, 120, 150 e 180 min. Foi observada a existência de um transporte materno-fetal, mas não feto-materna, de xilose para ambos períodos gestacionais. No Experimento 2, fêmeas prenhes foram abatidas nos Dias 90 ou 180 de gestação. Antes do abate (60 min), as fêmeas receberam uma solução de $10 \%$ de xilose por via intravenosa para a mensuração da transferência materno-fetal à xilose. Amostras de sangue materno e fetal, e dos fluídos amniótico e alantóide, foram coletadas após o abate para a determinação das concentrações de glicose e xilose. Foi observado um aumento no acúmulo de xilose nos subcompartimentos uterinos no final do segundo trimestre de gestação, demonstrando um aumento na taxa de transferência materno-fetal de xilose com a progressão da gestação. Em conclusão, a utilização da xilose mostrou-se válida como marcador biológico em estudos relacionados ao transporte placentário com potenciais implicações no crescimento do concepto.

Descritores: transporte placentário, bovinos, xilose, glicose, metabolismo. 


\section{INTRODUCTION}

A significant fraction of placental function is related to materno-fetal transfer and regulation of the amount and pattern of nutrients reaching the fetus [12]. Most substrates supplied to the placenta are metabolized by its tissues [12], with glucose accounting for $60 \%$ of the conceptus energy metabolism during pregnancy $[2,12,14]$. However, the study of transplacental glucose transfer is usually confounded by its metabolism in the uteroplacental tissues [31]. Xylose may be used as a tracer analog to circumvent this problem, since glucose and xylose enter cells by sharing components of the glucose transporter system [29,31]. Both molecules are rapidly transported across the placenta, and placental permeability to both sugars is assumed to be similar $[18,22]$. The exact mechanism of transplacental xylose transfer is not understood, but a carrier-mediated mechanism has been proposed for the sheep and rat placenta [31,32]. Under physiological conditions, xylose is slowly metabolized [8,37], enabling its use for the study of transplacental substrate transfer in humans [18], guinea pigs [22], sheep [31], and rats [32].

Results from studies in humans [18] and rats [32] have verified the materno-fetal unidirectional nature of xylose placental transfer, where xylose accumulation in the uterine compartments, including the fetus, closely reflects its transport. Conversely, results obtained from guinea pigs [22] and sheep [31] suggested the existence of a feto-maternal transfer. By the examination of the transplacental xylose transfer in bovine pregnancies, the aims of this study, were (a) to evaluate the rate of plasma xylose disappearance in pregnant and nonpregnant females, (b) to verify the existence of a feto-maternal transplacental xylose transfer, and (c) to assess the materno-fetal placental permeability to xylose.

\section{MATERIALS AND METHODS}

All chemicals used in these experiments were from Sigma ${ }^{1}$ unless stated otherwise. All animals were from a similar genetic background (Angus x Hereford crosses) and origin, and were maintained under the same environmental, nutritional and general management conditions for the entire period of the experiments. All procedures conformed to the Guidelines for Care and Use of Laboratory Animals, National Research Council and were approved by the Institutional Animal Care and Use Committee (IACUC) of the University of California, Davis.

\section{Experiment 1. Plasma xylose disappearance in nonpregnant and pregnant females and feto-maternal placental xylose transport in bovine pregnancies}

\section{Maternal xylose plasma clearance}

Cycling, postpuerperium multiparous bovine females or Day-90 or Day-180 pregnant multiparous females bred by artificial insemination (AI) were used for the study of plasma xylose disappearance and xylose transfer from the allantoic fluid to the maternal plasma. At time zero $(t=0)$ a blood sample was drawn from nonpregnant $(\mathrm{n}=4)$ and pregnant females on Days 90 $(n=5)$ and $180(n=5)$ of gestation, followed by the slow infusion (about $9 \mathrm{~min}$ ) of a sterile phosphate-buffered saline (PBS) solution (1 mL/kg BW) containing $10 \%$ $(w / v)$ xylose into the jugular vein of each animal (jugular-infused animals). Subsequently, blood samples were collected from the contralateral jugular vein at 15, 30, $60,90,120,150$, and $180 \mathrm{~min}$ from the onset of the infusion. All blood samples in this study were taken by jugular venipuncture using a BD Vacutainer ${ }^{\circledR}$ system (20-gauge BD Vacutainer ${ }^{\circledR}$ multiple sample needles and holders, and BD Vacutainer ${ }^{\circledR}$ PST $^{\mathrm{TM}} 9.5 \mathrm{~mL}$ draw tubes containing lithium heparin). Upon collection, blood samples were immediately chilled on ice and centrifuged for 5 to $10 \mathrm{~min}$, and plasma was frozen at $-20^{\circ} \mathrm{C}$ pending analyses.

\section{Feto-maternal xylose transport - allantocentesis and allantoic infusion}

Days $90(n=3)$ and $180(n=3)$ pregnant females were immobilized in a hydraulic chute, and an epidural anesthesia was performed by the injection of $5 \mathrm{~mL}$ of a $2 \%$ lidocaine ${ }^{2}$ hydrochloride solution $\left(\right.$ Butler $^{\circledR} \mathrm{Li}$ docaine $2 \%$ Injectable). A blood sample was collected from the jugular vein $(\mathrm{t}=0)$. After perineal asepsis, a real-time, B-mode veterinary portable ultrasound scanner $^{3}$ equipped with a $5 \mathrm{MHz}$ convex sector-array transducer was used for the transvaginal ultrasoundguided aspiration of approximately $120 \mathrm{~mL}$ (Day 90 of gestation) or $300 \mathrm{~mL}$ (Day 180 of gestation) of allantoic fluid. In brief, a transvaginal device coupled to the ultrasound transducer was inserted into the vaginal canal. A $55 \mathrm{~cm}$ long 17-gauge double lumen Echotip $^{\circledast}$ needle $^{4}$ (V-BOAD-1755-L), with in-line stopper, was attached to a $50 \mathrm{~mL}$ polypropylene centrifuge tube connected to a regulated vacuum pump ${ }^{4}$ (V-MAR5000-MM) in one way, and to a 50-cc plastic syringe in the other. The needle was introduced into the trans- 
vaginal device. The uterus was manipulated rectally with one hand, while the transvaginal device and needle were controlled with the other hand. After the puncture of the vaginal, uterine and chorio-allantoic tissue layers, the needle was positioned into the allantoic cavity, posterior to the amnion. For the aspiration, the vacuum pressure was adjusted to approximately $-150 \mathrm{~mm} \mathrm{Hg}$, and the vacuum was pedal-controlled. Immediately after the aspiration, $120 \mathrm{~mL}$ (Day 90) or $300 \mathrm{~mL}$ (Day 180) of PBS containing $10 \%$ xylose was infused into the allantoic cavity (AF-infused animals). The xylose solution was infused by the use of a 50-cc plastic syringe connected to one of the needle's adaptors, while the other adaptor was blocked. Duration of infusion was $4.3 \pm 1.6$ min. Maternal blood samples were collected by jugular venipuncture $15,30,60,90,120,150$, and $180 \mathrm{~min}$ after the onset of the infusion, as for Experiment 1.

\section{Glucose and xylose measurements in maternal plasma}

Concentrations of glucose and xylose were determined in duplicates or triplicates in two replications in the maternal plasma by colorimetric assays. Absorbance (A) was measured in a preset spectrophotome$\operatorname{ter}^{5}$ (UV-160 A Recording Spectrophotometer). After jugular infusion, plasma of some animals collected at $\mathrm{t}=15$ min needed to be diluted to allow the absorbance readings to fall within the concentration range of our standards and the maximum reading capacity of the spectrophotometer. Glucose concentrations were determined using a glucose assay kit [35], which uses glucose oxidase and peroxidase to form a product with high absorbance at $505 \mathrm{~nm}$ (quinoneimine dye), following the manufacturer's recommendations. The A of all tubes, in duplicate, was measured at $505 \mathrm{~nm}$. The A of each reagent blank was subtracted from the \%A for the samples and standards read in the same run to obtain the change in \% A due to glucose. Xylose measurements were based on procedures described elsewhere [10, 20], which rely on the reaction of furfural, a byproduct compound of a thermoacidic conversion of pentoses and xylose, with phloroglucinol to form a chromogenic compound with molar absorbance at $545 \mathrm{~nm}$ wavelength. Test tubes were labeled for the reagent blank, standards, plasma blank, and samples (maternal and fetal plasma, amniotic and allantoic fluids). The plasma blank consisted of a pool of xylose-free plasma samples, and was obtained from the same animals at $t=0$, immediately before the xylose infusion. This pool was used for the entire analytical run for the correction for the low glucose cross-reactivity with the xylose assay. Twenty microliters of deionized water (reagent blank), plasma blank, standards, and samples were added to appropriately labeled tubes, in duplicates or triplicates. Then, $2 \mathrm{~mL}$ of color reagent were pipetted into each tube and gently mixed. At timed intervals, tubes were transferred to a block heater set at $105^{\circ} \mathrm{C}$, and incubated for exactly $5 \mathrm{~min}$. Tubes were removed from the heater and placed in ice to stop the reaction, following the preset timed intervals. The A of all tubes were sequentially measured at $545 \mathrm{~nm}$ against distilled-deionized water. The $\mathrm{A}$ of the reagent blank tubes, and the plasma blank tubes, were subtracted from the A for the samples and standards to obtain the change in A due to xylose.

\section{Experiment 2. Materno-fetal placental xylose transport in Day-90 and Day-180 bovine pregnancies}

\section{In vivo embryo production}

Control embryos were obtained after superovulation and AI of donor females (Angus or Angus-Hereford crosses) with an Angus sire [4]. Briefly, estrous cycles of donors and recipients were synchronized and a total of 36-44 iu of FSH-p ${ }^{6}$ (Oocyte Media Supplement ${ }^{\circledR}$ ) was given im to the donors, in decreasing doses, twice a day, for 4 consecutive days, starting on Day 9 or 10 of the estrous cycle. A dose of prostaglandin $\mathrm{F}_{2 \mathrm{a}}$ analogue $^{7}$ (dinoprost tromethamine, Lutalyse ${ }^{\circledR}$ ) $25 \mathrm{mg}$ was injected im to the donors along with the sixth and seventh injections of FSH-p. Estrus detection was performed every 4 to $6 \mathrm{~h}$, and AI was performed at 10-12 and 20-24 h after the onset of estrus. On Day 7 of development $(\mathrm{AI}=$ Day 0$)$, embryos were recovered nonsurgically by uterine flushing. Day-7 blastocysts and expanded blastocysts were nonsurgically transferred (ET) to recipients synchronous $( \pm 12 \mathrm{~h}$ ) to the donors. Pregnancy and fetal gender diagnoses were carried out per rectum on Days 27 and 60 of gestation, respectively, by means of ultrasonography using a real-time, B-mode veterinary portable ultrasound scanner (Aloka ${ }^{\mathrm{TM}} \mathrm{SSD}$ $500 \mathrm{~V}$ ) equipped with a $5 \mathrm{MHz}$ linear-array transducer.

\section{Collection of samples on Days 90 and 180 of gestation}

Pregnant females were slaughtered on Days 90 $(n=4)$ and $180(n=4)$ of gestation, after a 12-h fast, for collection of the pregnant uteri and their respective fetuses and placentas, and maternal and fetal plasma and associated fetal fluids (amniotic and allantoic fluids). 
Sixty minutes before slaughter, PBS containing $10 \%$ (w/v) xylose (100 mg/kg BW) was infused into the jugular vein of each animal $(1 \mathrm{~mL} / \mathrm{kg}$ BW) to quantify the placental transfer of xylose from the dam to the fetus and uterine subcompartments. Maternal blood samples were obtained at the time of exsanguination. The pregnant uterine tract was dissected along the major curvature, by cutting only the uterine wall and the chorioallantoic membranes. Allantoic fluid was carefully poured into large graduated cylinders for the measurement of its total volume, and after fluid mixing, samples were centrifuged, frozen, and stored at $-80^{\circ} \mathrm{C}$. Amniotic fluid was collected and processed in the same way as for the allantoic fluid. The umbilical cord was clamped, excised, and the fetus removed. Fetal blood was collected by cardiopuncture while the fetal heart was, in the great majority of fetuses, still beating. Maternal and fetal blood and amniotic and allantoic fluids were centrifuged, and fluids were frozen and stored at $-80^{\circ} \mathrm{C}$.

\section{Glucose and xylose measurements in maternal and fetal plasma and in fetal fluids}

Due to both the high concentrations of fructose in the fetal plasma and fetal fluids in the cow [5] and the cross-reactivity within the xylose colorimetric assay, the identification and quantification of maternal and fetal plasma and fetal fluid xylose and glucose concentrations were performed on a Waters 840 HPLC system ${ }^{8}$ coupled to a Waters refractive index detector. Instrument conditions included a flow rate of $0.6 \mathrm{~mL} / \mathrm{min}$ water utilizing an Aminex HPX-87C column (Millipore), 300 x $7.8 \mathrm{~mm}$, at an operating temperature of $85^{\circ} \mathrm{C}$, for an isocratic analysis time of $30 \mathrm{~min}$. Sample preparation employed the Centrifree ${ }^{\circledR}$ micro partition device ${ }^{8}$ (Millipore) with a regenerated cellulose membrane of 30,000 nominal molecular weight cut-off in a fixed-angle centrifuge, and centrifuged at 2,000 $\mathrm{g}$ for $60 \mathrm{~min}$. A total of $100 \mu \mathrm{L}$ was used per sample.

Standard curves for the colorimetric and chromatographic assays were obtained for each assay using multilevel glucose $(100,200,300,400 \mathrm{mg} / \mathrm{dL}$ glucose) or xylose $(100,200,300,400 \mathrm{mg} / \mathrm{dL}$ xylose $)$ standards. Glucose and xylose standards were included in the xylose and glucose colorimetric assays, respectively, for the evaluation of cross-reactivity between methods. In Experiment 2, total accumulated sugars in the amniotic and allantoic fluids were computed after determination of the glucose and xylose concentrations, based on the total volume collected for each fluid. In- tra- and inter-assay variations ranged from 3.7 to $6.9 \%$ and 1.5 to $10.7 \%$ for the glucose and xylose colorimetric assays, respectively, and were $1.2 \%$ and $13.8 \%$ for the HPLC-based analysis, respectively.

\section{Statistical analyses}

Data analyses were done in Proc GLM of SAS (SAS Institute, Cary, NC, USA). Data obtained in Experiment 1 were analyzed using a repeated measures model including reproductive status (nonpregnant or pregnant, and stage of gestation), xylose infusion site (jugular, allantoic fluid), time period ( $\mathrm{t}=0$ to $\mathrm{t}=180 \mathrm{~min}$ ) and individual cows. Also, single degrees of freedom (DF) contrasts (t-test) were performed on reproductive status by infusion site model treatment classes, and linear contrasts of average allantoic fluid infusion versus jugular infusion were determined for both Day- 90 and Day-180 groups. Data from Experiment 2 were analyzed by ANOVA, considering Day $(90,180)$ as main effect in the analyses. Pairwise comparisons were performed by least square means (LSM). A simple Pearson's correlation test was used for the analysis of relationships between traits.

\section{RESULTS}

\section{Experiment 1}

Mean body weights (BW) and body condition scores (BCS, ranging from 1 , very thin, to 9 , very fat) were, respectively, $458.8 \pm 43.2 \mathrm{~kg}$ and $5.3 \pm 0.3$ for nonpregnant females, $483.2 \pm 92.5 \mathrm{~kg}$ and $6.1 \pm 0.7$ for pregnant females on Day 90 of gestation, and 571.4 $\pm 42.4 \mathrm{~kg}$ and $6.1 \pm 0.8$ for pregnant females on Day 180 of gestation, respectively. Maternal mean BW, but not BCS, was different between nonpregnant or pregnant (Day 90) females, and pregnant females on Day 180 of gestation $(\mathrm{P}<0.05)$. Mean duration of the jugular infusions was $9 \pm 3$ min and did not differ among animals or groups. For the allantois-infused females (AF-infused animals), the allantoic fluid and the xylose solution created echogenic turbulence during infusion, making the process of infusion readily visible by ultrasonography and providing visual control over the technique. Duration of allantoic infusion was $4.3 \pm 1.6$ min and did not differ between groups. All AF-infused cows aborted within $10 \mathrm{~d}$ following the experiment.

The reproductive status (nonpregnant or pregnant, and stage of gestation), site of xylose infusion (jugular or allantoic fluid) and time period ( $\mathrm{t}=0$ to $\mathrm{t}=180$ ) 
were significantly associated with plasma glucose and xylose concentrations (Figure 1, $\mathrm{P}<0.01$ ). Depending on the reproductive status and site of xylose infusion, cows had significantly different $(\mathrm{P}<0.0001)$ plasma glucose and xylose concentrations (Figure 1). Glucose and xylose values within animals were different over time $(\mathrm{P}<0.001)$. Considering only the pregnant females, the linear contrasts of mean allantois infusion versus jugular infusion revealed significant differences between animals infused in the jugular and the allantoic cavity for both glucose and xylose concentrations $(\mathrm{P}<0.0001)$.

Nonpregnant cows had significantly lower plasma glucose concentrations than pregnant cows infused in the jugular vein (Figure 1, $\mathrm{P}<0.01$ ), and tended to have lower glycemia than pregnant cows infused in the allantoic fluid $(\mathrm{P}<0.07)$. Pregnant females had higher glycemia than nonpregnant animals (Figure 1a), even before the xylose infusion and irrespective of the site of infusion and stage of gestation. In general, the infusion of xylose in the jugular vein was followed by an increase in glucose concentrations over time in the plasma of pregnant cows on Day 90 of gestation compared with animals infused in the allantoic fluid (Days 90$\mathrm{AF}$ and 180-AF) and nonpregnant cows that had been infused in the jugular vein $(\mathrm{P}<0.07)$. Glucose levels at $\mathrm{t}=0$ were lower than from $\mathrm{t}=30$ to $\mathrm{t}=180 \min (\mathrm{P}<0.05)$; at $\mathrm{t}=15 \mathrm{~min}$, glycemia was lower, or tended to be lower, than at $\mathrm{t}=60$ to $\mathrm{t}=180(\mathrm{P}<0.09)$. Within groups, glucose concentrations did not change significantly over time in nonpregnant animals or animals subjected to allantoic infusion on Day 180 of gestation $(\mathrm{P}>0.05)$. Pregnant animals infused in the jugular on Days 90 and 180 of gestation, or infused in the allantois on Day 90, displayed an increase in glucose concentrations after $\mathrm{t}=30$, $\mathrm{t}=90$, and $\mathrm{t}=150 \mathrm{~min}$, respectively.

Plasma xylose concentrations following jugular infusion were high at $\mathrm{t}=15 \mathrm{~min}$ and exhibited a steady exponential decline during the collection period (Figure 1b). Conversely, in AF-infused animals xylose did not appear to have been transferred from the allantois to the maternal system, since plasma xylose concentrations were negligible $(\sim 0 \mathrm{mM})$, falling around or below the limits of sensitivity of the assay $(0.3 \mathrm{mM}$ or lower), and did not change over time, being significantly lower than jugular-infused animals $(\mathrm{P}<0.0001)$. This suggests that no or negligible feto-maternal xylose transfer occurred in AF-infused animals. Xylose in the plasma of nonpregnant females was significantly higher at $\mathrm{t}=15$ and $\mathrm{t}=30 \mathrm{~min}$ than in jugular-infused pregnant animals $(\mathrm{P}<0.039)$ but became similar afterwards. Within groups, plasma xylose concentrations from $t=15$ to $\mathrm{t}=60$ were different from one another and were higher than from $\mathrm{t}=90$ to $\mathrm{t}=180 \mathrm{~min}(\mathrm{P}<0.05)$. After $\mathrm{t}=90 \mathrm{~min}$, plasma xylose levels were similar among time points (Figure 1b).

\section{Experiment 2}

At the time of slaughter, maternal mean body weights $(480.5 \pm 57.8$ and $542.5 \pm 29.9)$, and BCS $(6.2 \pm 0.2$ and $6.3 \pm 0.5)$ were different $(\mathrm{P}<0.0001)$ for days 90 and 180 of gestation, respectively. Time from infusion to sampling maternal blood was 61 to $66 \mathrm{~min}$, and from infusion to sampling fetal blood and uterine fluids was 73 to $82 \mathrm{~min}$ and did not differ between days of slaughter. Data regarding the comparison of conceptus physical traits were described previously [5] and are summarized in Table 1.

Xylose was detected in fetal plasma and fluids at both gestation periods. Figure 2 displays glucose and xylose concentrations in the plasma (maternal or fetal) and uterine fluids (amniotic or allantoic) of recipients on Days 90 and 180 of gestation. Xylose concentrations in the allantoic fluid were higher on Day 180 than on Day 90 of pregnancy $(\mathrm{P}<0.05)$. No other temporal differences were observed in the maternal or fetal plasma and amniotic or allantoic fluid for either sugar. Maternal plasma glucose and xylose concentrations in Experiment 2 did not differ from the values obtained at $\mathrm{t}=60 \mathrm{~min}$ in jugular-infused animals in Experiment 1. Concentrations of glucose and xylose were 2- to 5fold lower in the fetal plasma and associated fluids than in the maternal plasma. Concentrations of xylo-se in the amniotic fluid were positively correlated with uterine, placental and fetal traits $(0.710<\mathrm{r}<0.806, \mathrm{P}<0.01)$, whereas concentrations of glucose in the fetal plasma and in the uterine fluids were negatively correlated with those same physical traits $(-0.638<\mathrm{r}<-0.908, \mathrm{P}<0.0001)$. Total accumulations of xylose and glucose in the allantoic fluid and in total fluids were positively correlated with one another $(0.879<\mathrm{r}<0.930, \mathrm{P}<0.0001)$.

\section{DISCUSSION}

Like other mammals, domestic ruminants have evolved adaptive homeostatic mechanisms to accommodate the organism through pregnancy [3]. The differences in maternal body weights as gestation advances, as seen in these experiments, is an example of such changes, and these increments in weight are in part due 

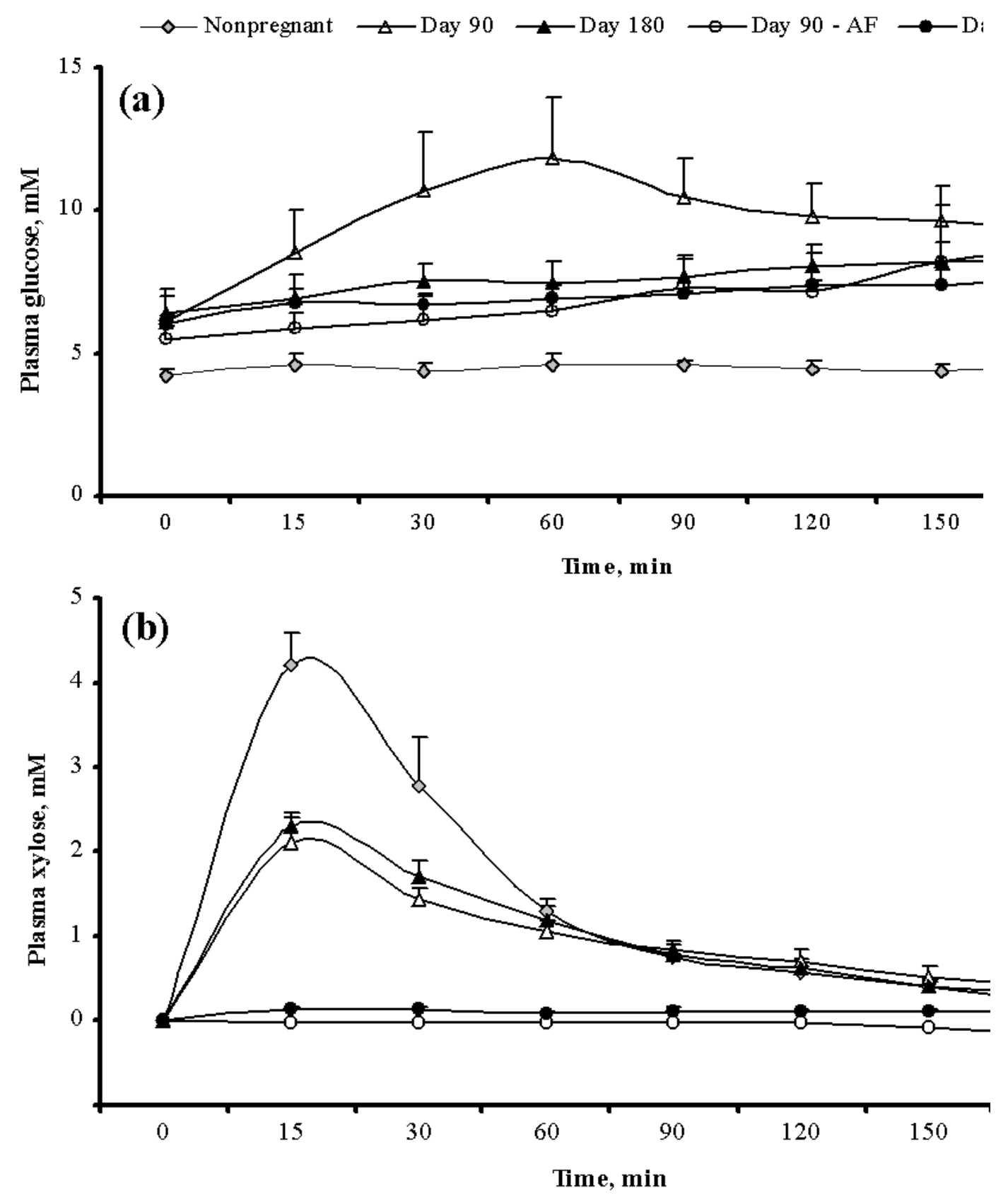

Figure 1. Plasma sugar concentrations $(\mathrm{mM})$ of nonpregnant and pregnant bovine females from $\mathrm{t}=0$ (pre-xylose infusion) to $\mathrm{t}=180 \mathrm{~min}$ after jugular or allantoic $(\mathrm{AF})$ xylose infusion (LSM $\pm \mathrm{SEM}$ ). (a) Glucose, (b) Xylose. For differences between and within groups and over time, follow text.

to changes in the maternal system per se and to the growth and development of the uterine and conceptus tissues [33]. The volume of distribution for compounds like xylose also changes over the course of pregnancy as blood and interstitial fluid volumes expand during this period [27,34]. The volume of distribution of xylose is somewhat larger than the extracellular fluid volume [37] thus, xylose levels were expected initially to be higher in open animals and lower in pregnant females due to sequestration in body fluids [34]. Our results in Experiment 1 were consistent with this concept.
In Experiment 1, plasma glucose in the nonpregnant females $(3.7 \pm 0.4 \mathrm{mM}$, ranging from 2.9 to 4.7 $\mathrm{mM}$ ) fell within the normal range of plasma glucose concentration (2.5 to $4.2 \mathrm{mM}$ ) in the bovine [7]. Pregnant females had slightly higher plasma glucose levels at $\mathrm{t}=0(5.0 \pm 1.0 \mathrm{mM}$, ranging from 3.4 to $7.2 \mathrm{mM})$, and those levels were within or close to normal ranges reported previously [26] but higher than for cows in mid- to late gestation $[14,28]$. Such findings may reflect the physiological alterations that pregnancy imposes on the dam, since metabolism, extracellular fluid 

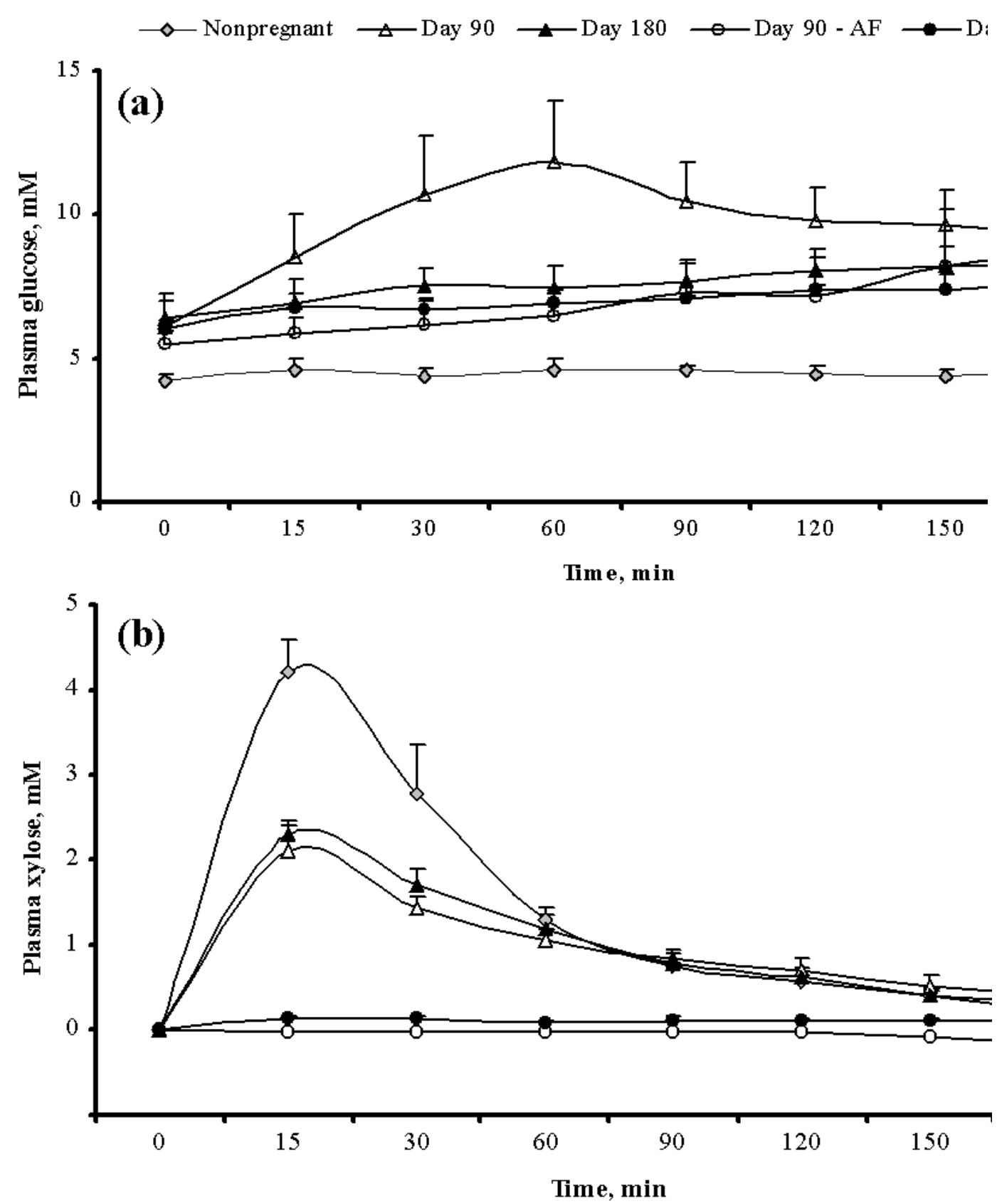

Figure 2. Sugar concentrations (mM) in the plasma and uterine fluids of bovine pregnancies on Days 90 and 180 of gestation (LSM \pm SEM). (a) Glucose, (b) Xylose. ${ }^{\mathrm{a}, \mathrm{b}}$ Numbers in the same group of fluid type without common superscripts differ, $\mathrm{P}<0.05$.

volume, and peripheral vascular resistance change during pregnancy, essentially for pregnant animals during the second and third trimester of gestation. Normally, nonpregnant animals have not only lower plasma glucose levels but also lower extracellular fluid volume and do not possess the pregnant uterine compartment to affect vascular resistance and hemodynamic changes to the system. In addition to the higher maternal plasma glucose in pregnant compared with nonpregnant animals, glucose concentrations gradually increased in the plasma of pregnant females 15 to $30 \mathrm{~min}$

\begin{tabular}{|c|c|c|}
\hline Traits & Day 90 & Day 180 \\
\hline Fetal weight, kg & $0.146^{a} \pm 0.013$ & $6.462^{b} \pm 0.180$ \\
\hline Fetal femoral length, mm & $23.3^{\mathrm{a}} \pm 1.4$ & $100.3^{b} \pm 1.5$ \\
\hline Total placentome weight, kg & $0.124^{a} \pm 0.037$ & $2.23^{b} \pm 0.03$ \\
\hline Total placentome S.A. ${ }^{*} \mathrm{dm}^{2}$ & $2.01^{a} \pm 0.47$ & $24.60^{\mathrm{b}} \pm 1.29$ \\
\hline
\end{tabular}


after the xylose infusion. This elevation was also seen in AF-infused animals. This could be a consequence of the xylose infusion since both sugars compete for common cell-membrane transporters [29,31]. However, this is a controversial issue, since some investigators demonstrated that iv xylose administration of $0.5 \mathrm{~g} / \mathrm{kg}$ to normal human individuals did not affect plasma glucose or insulin levels [9], whereas others observed glycemic changes ranging from 0 to $32 \%$ after iv xylose infusion in human subjects [37]. Moreover, AF-infused animals did not show a parallel increase in maternal plasma xylose over the period of study in Experiment 1, refuting the concept of membrane transporter competition. Alternatively, the process of blood collection for a period of 180 min always imposes a certain level of excitement and stress on the animals, which may be a factor associated with the slight elevation in plasma glucose, even in the AF-infused animals. Excitement and stress are factors commonly associated with short- or long-term hyperglycemia, which may be mediated by catecholamine and glucocorticoid hormones [7].

Concentrations of glucose in fetal plasma in both gestation periods were 20 to $30 \%$ of maternal levels, which is consistent with previous reports in cattle [26]. Placental glucose consumption has been implicated as a primary factor responsible for fetal hypoglycemia [30], and some results have demonstrated that fetal glucose uptake varies between 11 and $17 \%$ of total uterine uptake around Day 180 of gestation [13,25], with the uteroplacental tissue consuming $60 \%$ or more of this substrate for its own metabolic functions [3]. Since concentrations of glucose in the fluid types (fetal plasma, amniotic and allantoic fluids) negatively correlated with the uterine, placental and fetal physical traits, this mechanism reflects the increase in substrate utilization in the last 3 to 4 months of gestation when $90 \%$ of the conceptus growth occurs [12].

The appearance of xylose in the uterine subcompartments reflects its accumulation probably due to the low metabolic turnover of xylose by the placental tissue, which is unable to process xylose at the same rate as glucose. Thus, the xylose taken up by the placental tissue may be 'dumped' into the fetal system. Hypothetically, the amount of a nonmetabolizable substrate accumulated and/or transferred to the fetal system may depend on the size and/or metabolic activity of the placental tissue. With the increase in uterine and conceptus size and, consequently, their metabolic demands, more systemic blood is diverted to the pregnant uterus as pregnancy nears its end. Larger or more active placentas may accumulate and transfer more of those substrates. In addition, greater uterine blood flow is associated with greater fetal and placental weight and greater fetal growth rates in late gestation.

More maternal xylose was transferred through the placental tissue on Day 180 of gestation than on Day 90, which was demonstrated by the differences in xylose accumulated in the allantoic fluid in animals in this period. This is probably a direct reflection of the increase in placental glucose transfer capacity by the second trimester of pregnancy. Glucose is transported into cells by an extensive family of sugar transporters composed of 13 isomeric facilitative sugar transporter proteins (Glut-1 to -12 and HMIT1: glucose transporters; SLC2A genes: solute carriers 2A), and three to six $\mathrm{Na}^{+}-$ dependent (SGLT-1 to -6; SLC5A genes: solute carriers $5 A)$ glucose transporters $[15,19,21,23,36]$. The various isoforms of glucose transporters have different kinetic features, localizations and temporal, tissue-specific characteristics [19]. Glut-1 is the ubiquitous Glut isoform present in mammalian cells and embryos $[1,15,19,21$, $23,36]$. In human placenta, Glut-1 is the primary transporter of glucose, which is asymmetrically distributed between the microvillous and basal membranes of the syncytiotrophoblast, but Glut-3 (arterial vascular endothelium) and the insulin-dependent transporter Glut-4 (intravillous stromal cells) are also reported to be present in the human placental tissue [19]. Interestingly, Glut-3 is the major transporter isoform in the rat placenta and becomes an increasingly prominent isoform as gestation progresses in sheep [11,24]. This change in Glut-3 density seemed to account for the 5-fold increase in glucose transport capacity of the sheep placenta during mid- to late pregnancy [3]. However, we recently reported no differences in the relative transcription of the glucose transporters Glut-1, Glut-3, and Glut-5 (fructosespecific membrane transporter) in placentomes between in vivo- and in vitro-derived pregnancies on Days 90 and 180 of gestation [5]. Even if the density of glucose transporters remains unchanged between both gestation periods, placental mass increases 18-fold from Day 90 to 180 of gestation [5], which also increases the surface area for exchange. Nevertheless, differences in xylose levels between gestation days also indicate divergences in placental metabolism and not only in total transport capacity.

After jugular infusion, xylose disappearance from the maternal plasma in Experiment 1 appeared to follow 
first-order kinetics, as suggested by a previous report after iv xylose infusions in humans [37]. It is unlikely that metabolism significantly affected the concentration of xylose in the maternal and uterine compartmental fluids at $\mathrm{t}=60 \mathrm{~min}$ in Experiment 2. The halflife for xylose disappearance from blood was reported to be 60 to $70 \mathrm{~min}(0.98 \% / \mathrm{min})$ in the nonadapted human [37]. In addition, xylose is slowly metabolized, and the main route of elimination is renal [8]. In a 24-h period following iv xylose infusion in humans, approximately 42 to $50 \%$ of the total xylose elimination is renal, with a net renal tubular reabsorption of this sugar of $13 \%$ of the glomerular filtration rate, $5 \%$ is eliminated unchanged in bile, 15 to $27 \%$ is slowly metabolized in the liver to $\mathrm{CO}_{2}$, via the pentose phosphate pathway, and $15 \%$ is converted to D-threitol $[8,9,37]$. The clearance rate of xylose in these experiments varied from 1 to $2 \% / \mathrm{min}$, consistent with data from the literature [37], indicating that xylose disappearance from maternal plasma is likely due to renal clearance. The positive correlations between concentrations of xylose in the amniotic fluid or total xylose in the amniotic and allantoic fluids and physical traits in Experiment 2 may indicate that xylose, as a slow-metabolizing substrate, could be cleared from the fetal plasma, perhaps by renal filtration, accumulating in the uterine fluids. Once in the fetal bladder, xylose, along with urine, can be excreted either into the amnion through the urethra or into the allantois through the urachus $[6,17]$.

The range in maternal glucose and xylose concentrations observed at $\mathrm{t}=60$ min for jugular-infused pregnant females was similar between Experiments 1 and 2, which allowed us to perform temporal-spatial extrapolations of the data in both experiments. The infusion of xylose into the allantoic cavity in Experiment 1 resulted in no or negligible net xylose transfer to the maternal system. Concentrations of xylose in the maternal plasma of AF-infused animals were not different from zero during the period of the study, which can be interpreted in at least three different ways:

1. Transfer of xylose across the placenta is in fact unidirectional;

2. The dose of xylose used for the AF-infusion might have been inadequately low;

3. The site of infusion (allantoic fluid) may not have allowed a quick turnover of molecules or compounds such as xylose to re-enter the fetal circulation.

The first alternative would confirm the study's hypothesis, that the transfer of xylose across the placen- ta is in fact unidirectional (materno-fetal transfer), and no transfer in the feto-maternal direction occurs. This agrees with results for the human and rat placentas [18, 32], but disagrees with those for the guinea pig and sheep placentas [22,31]. If a feto-maternal transfer pathway exists for xylose, it has to be via an active, energydependent mechanism, which was suggested in the guinea pig for the feto-maternal direction [22]. Since fetal concentrations at $\mathrm{t}=60 \mathrm{~min}$ were half that maternal plasma concentrations (for jugular-infused animals), transport would have to be against its concentration gradient.

The second alternative is that the dose of $x y-$ lose used for the AF-infusion might have been inadequately low; if feto-maternal transfer occurs, low doses may not reach values above the limits of sensitivity of the xylose assay in the maternal plasma. For the study of the transplacental transfer of xylose across the rat placenta, a xylose dose of $200 \mathrm{mg} / \mathrm{kg}$ BW for the maternofetal transfer and $50 \mathrm{mg} / \mathrm{kg}$ for the feto-maternal transfer, and $10 \%$ xylose solutions were used intravenously for the study of placental permeability to xylose in the guinea pig [22]. We adopted a dose of $100 \mathrm{mg} / \mathrm{kg}$ for the jugular infusion and a total of $12 \mathrm{~g}(25.1 \pm 0.8 \mathrm{mg} /$ $\mathrm{kg}$ maternal BW) and $30 \mathrm{~g}(56.2 \pm 1.45 \mathrm{mg} / \mathrm{kg}$ maternal BW) of xylose for the allantoic fluid infusion on Days 90 and 180 of pregnancy, respectively. However, xylose has been extensively used for the study of carbohydrate or pan-malabsorption syndromes, with the xylose absorption test $[8,10,20,37]$. For this purpose, xylose dosages given orally usually are $100 \mathrm{mg} / \mathrm{kg}$ for oral solutions, or 5 to $25 \mathrm{~g}$ of xylose, 5 to $20 \%$ solutions, and measurements are carried out in the patient's plasma or urine for 1 to $8 \mathrm{~h}$ thereafter. Usually, in such conditions, xylose levels reach values 5- to 10-fold higher than the limit of sensitivity of the xylose assay [20]. Consequently, it is unlikely that xylose dosages were inadequate in this study.

Thirdly, the site of infusion (allantoic fluid) may not have allowed a quick turnover of molecules or compounds such as xylose to re-enter the fetal circulation during the time of sampling used in this study (180min). Water and solutes can pass between amniotic fluid or allantoic fluid and fetal blood perfusing the amnion and the chorioallantois (intramembranous exchange and/or paracellular pathways), for an unknown rate of exchange [6]. Xylose either does not re-enter feto-placental circulation from the allantois, or no net feto-maternal transfer occurs after the infusion into the allantoic cavity. Yet, a materno-fetal xylose transfer occurs in the bo- 
vine placenta, as observed in Experiment 2, and if $\mathrm{xy}$ lose is not recycled, xylose accumulation into the uterine compartments closely reflects its placental transport, as suggested by others [32], with xylose remaining trapped in the uterine subcompartments.

\section{CONCLUSIONS}

Under the conditions of this study, a maternofetal but not a feto-maternal transfer of xylose through the bovine placenta was observed on Days 90 and 180 of gestation.

An association between uterine, placental, fetal and xylose placental transfer was apparent as concepti presented higher concentrations and accumulation of xylose in the fetal plasma and allantoic fluid on Day 180 of gestation, which indirectly demonstrates an increased transfer capacity at that stage of gestation than at earlier stages. More xylose seemed to enter and/or remain trapped in the uterine compartments as pregnancy advanced, as pregnancies on Day 180 of gestation displayed higher xylose concentrations in allantoic fluid. Such findings were anticipated since placental transport capacity or placental function should increase as metabolic demands also increase towards the end of pregnancy.

Although xylose was a valid tracer for transplacental transport studies in cattle in this study, further studies are required to determine mechanisms, kinetics, and fate of the xylose transport through the bovine placenta.

Acknowledgements. The authors thank Mrs. A.L. Moyer, Mr. M.L. Sween and Mr. D.J. Kominek for their excellent technical assistance, and interns, students and staff at the Beef Cattle Facilities of the Department of Animal Science and the Sierra Foothill Research and Extension Center of the University of California for their assistance.

\section{SOURCES AND MANUFACTURERS}

${ }^{1}$ Sigma Chemical Co., St. Louis, MO, USA.

${ }^{2}$ The Butler Company, Columbus, OH, USA.

${ }^{3}$ Aloka $^{\mathrm{TM}}$ SSD-500V

${ }^{4}$ Cook $^{\circledR}$ Veterinary Products Inc., Spencer, IN, USA.

${ }^{5}$ Shimadzu Co., Analytical Instruments Division, Kyoto, Japan. ${ }^{6}$ Sioux Biochemical, Sioux Center, IA, USA.

${ }^{7}$ Pharmacia-Upjohn Co., Kalamazoo, MI, USA.

${ }^{8}$ Millipore Corporation, Milford, MA, USA.

\section{REFERÊNCIAS}

1 Augustin R., Pocar P., Navarrete-Santos A., Wrenzycki C., Gandolfi F., Niemann H. \& Fisher B. 2001. Glucose transporter expression is developmentally regulated in in vitro derived bovine preimplantation embryos. Molecular Reproduction and Development. 60: 370-376.

2 Battaglia F.C. \& Meschia G. 1978. Principal substrates of fetal metabolism. Physiological Reviews. 58: 499-527.

3 Bell A.W., Hay W.W. \& Ehrhardt R.A. 1999. Placental transport of nutrients and its implications for fetal growth. Journal of Reproduction and Fertility. 4 (Suppl): 401-410.

4 Bertolini M., Mason J.B., BeamS.W., Carneiro G.F., Sween M.L., MoyerA.L., Famula T.R., Sainz R.D. \& Anderson G.B. 2002. Morphology and morphometry of in vivo- and in vitro-produced bovine concepti from early pregnancy to term and association with high birth weights. Theriogenology. 58: 973-994.

5 Bertolini M., Moyer A.L., Mason J.B., Batchelder C.A., Hoffert K.A., Bertolini L.R., Carneiro G.F., Cargill S.L., Famula T.R., Calvert C.C., Sainz R.D. \& Anderson G.B. 2004. Evidence of increased substrate availability to in vitro-derived bovine foetuses and association with accelerated conceptus growth. Reproduction. 128: 341-354.

6 Brace R.A. 1995. Progress toward understanding the regulation of amniotic fluid volume: water and solutes fluxes in and through the fetal membranes. Placenta. 16: 1-18.

7 Carlson G.P. 1996. Clinical chemistry tests. In: Smith B.P. (Ed). Large Animal Internal Medicine. Saint Louis: Mosby-Year Book, pp.441-469.

8 Craig R.M. \& Atkinson A.J. 1988. D-xylose testing: a review. Gastroenterology. 95: 223-231.

9 Demetrakopoulos G.E. \& Amos H. 1978. Xylose and xylitol: metabolism, physiology and nutritional value. World Review of Nutrition and Dietetics. 32: 96-122.

10 Eberts T.J., Sample R.H.B., Glick M.R. \& Ellis G.H. 1979. A simplified, colorimetric micromethod for xylose in serum or urine, with phloroglucinol. Clinical Chemistry. 25: 1440-1443.

11 Ehrhardt R.A. \& Bell A.W. 1997. Developmental increase in glucose transporter concentration in the sheep placenta. The American Journal of Physiology. 273: R1132-R1141.

12 Ferrell C.L. 1989. Placental regulation of fetal growth. In: Campion D.R., Hausman G.J. \& Martin R.J. (Eds). Animal Growth Regulation. New York: Plenum Press, pp.1-19. 
13 Ferrell C.L. 1991. Maternal and fetal influences on uterine and conceptus development in the cow: II. Blood flow and nutrient flux. Journal of Animal Science. 69: 1954-1965.

14 Ferrell C.L. \& Reynolds L.P. 1992. Uterine and umbilical blood flows and net nutrient uptake by fetuses and uteroplacental tissues of cows gravid with either single or twin fetuses. Journal of Animal Science. 70: 426-433.

15 Girniene J., Tatibouet A., Sacckus A., Yang J., Holman G.D. \& Rollin P. 2003. Inhibition of the D-fructose transporter protein GLUT5 by fused-ring glyco-1,3-oxazolididn-2-thiones and -oxazolindin-2-ones. Carbohydrate Research. 338: $711-719$.

16 Gluckman P.D. \& Liggins G.C. 1984. Regulation of fetal growth. In: Beard R.W. \& Nathanielsz P.W. (Eds). Fetal Physiology and Medicine: The Basis of Perinatology. London: Butterworths, pp.511-557.

17 Gresham E.L., Rankin J.H.G., Makowski E.L., Meschia G. \& Battaglia F.C. 1972. An evaluation of fetal renal function in a chronic sheep preparation. The Journal of Clinical Investigation. 51: 149-156.

18 Holmberg N.G., Kaplan B., Karvonen M.J., Lind J. \& Malm M. 1956. Permeability of human placenta to glucose, fructose, and xylose. Acta Physiologica Scandinavica. 36: 291-299.

19 Illsley N.P. 2000. Glucose transporters in the human placenta. Placenta. 21: 14-22.

20 Johnson S.L., Bliss M., Mayersohn M. \& Conrad K.A. 1984. Phloroglucinol-based colorimetry of xylose in plasma and urine compared with a specific gas-chromatographic procedure. Clinical Chemistry. 30: 1571-1574.

21 Joost H.G. \& Thorens B. 2001. The extended GLUT-family of sugar/polyol transport facilitators: nomenclature, sequence characteristics, and potential function of its novel members (review). Molecular Membrane Biology. 18: 247-256.

22 Karvonen M.J., Laamanen A. \& Raiha N. 1956. Lack of effect of oxygen tension upon the permeability of the guinea pig placenta to d(+)xylose and sorbose. Acta Physiologica Scandinavica. 36: 245-249.

23 Medina R.A. \& Owen G.I. 2002. Glucose transporters: expression, regulation and cancer. Biological Research. 35: 9-26.

24 Mueckler M. 1994. Facilitative glucose transporters. European Journal of Biochemistry. 219: 713-725.

25 Reynolds L.P., Ferrell C.L., Robertson D.A. \& Ford S.P. 1986. Metabolism of the gravid uterus, fetus and utero-placenta at several stages of gestation in cows. The Journal of Agricultural Science of Cambridge. 106: 437-444.

26 Reynolds L.P., Ferrell C.L., Robertson D.A. \& Klindt J. 1990. Growth hormone, insulin and glucose concentrations in bovine fetal and maternal plasmas at several stages of gestation. Journal of Animal Science. 68: 725-733.

27 Rosso P. 1981. Nutrition and maternal-fetal exchange. The American Journal of Clinical Nutrition. 34: 744-755.

28 Sano H., Nakai M., Kondo T. \& Terashima Y. 1991. Insulin responsiveness to glucose and tissue responsiveness to insulin in lactating, pregnant, and nonpregnant, nonlactating beef cows. Journal of Animal Science. 69: 1122-1127.

29 Scharrer E. \& Grenacher B. 2000. $\mathrm{Na}^{+}$-dependent transport of D-xylose by bovine intestinal brush border membrane vesicles (BBMV) is inhibited by various pentoses and hexoses. Journal of the American Veterinary Medical Association. 47: 617-626.

30 Simmons M.A., Battaglia F.C. \& Meschia G. 1979. Placental transfer of glucose. Journal of Developmental Physiology. 1: 227-243.

31 Stacey T.E., Weedon A.P., Haworth C., Ward R.H.T. \& Boyd R.D.H. 1978. Feto-maternal transfer of glucose analogues by sheep placenta. The American Journal of Physiology. 234: E32-37.

32 Staud F., Fendrich Z., Karlícek R. \& Pávek P. 1998. Unidirectional transfer of d-xylose across the rat placenta. Clinical and Experimental Pharmacology \& Physiology. 25: 54-56.

33 Scheaffer A.N., Caton J.S., Bauer M.L. \& Reynolds L.P. 2001. Influence of pregnancy on body weight, ruminal characteristics, and visceral organ mass in beef heifers. Journal of Animal Science. 79: 2481-2490.

34 Tietz N.W., Rinker A.D. \& Henderson A.R. 1986. Gastric, pancreatic, and intestinal function. In: Tietz N.W. (Ed). Textbook of Clinical Chemistry. Philadelphia: W.B. Saunders Co., pp.1434-1494.

35 Trinder P. 1969. Determination of glucose in blood using glucose oxidase with an alternative oxygen acceptor. Annals of Clinical Biochemistry. 6: 24-27.

36 Wood I.S. \& Trayhurn P. 2003. Glucose transporters (GLUT and SGLT): expanded families of sugar transport proteins. The British Journal of Nutrition. 89: 3-9.

37 Wyngaarden J.B., Segal S. \& Foley J.B. 1957. Physiological disposition and metabolic fate of infused pentoses in man. The Journal of Clinical Investigation. 36: 1395-1407.

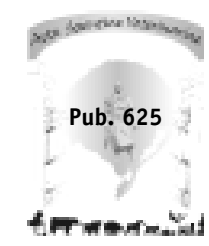

